\title{
Das Ruas ao Shopping: o crescimento do Comércio Informal nas ruas de Santa Maria - RS
}

\author{
Matheus Rosa Pinto* \\ Jorge Luiz da Cunha**
}

Resumo: O artigo em questão trata do desenvolvimento do comércio informal na cidade de Santa Maria - RS entre os anos de 1980 até 2011, abordando de que forma deu-se a organização inicial dos trabalhadores informais nas principais ruas da cidade, passando pela fundação do Camelódromo municipal em 1991, até a posterior transferência dos comerciários para o Shopping Independência em 2011. Além do mencionado acima, o estudo traz considerações sobre o conceito de trabalho informal, as principais atividades desempenhadas, a situação econômica e trabalhista na época, tal como, algumas exposições a respeito dos trabalhadores formais, informais em uma cidade do centro do estado do Rio Grande do Sul.

Palavras-chave: Comércio Informal; Camelódromo; Shopping Independência.

Abstract: The article in question deals with the development of informal trade in the city of Santa Maria - RS between the years 1980 to 2011, addressing how it gave the initial organization of informal workers in the main streets of the city, through the foundation of the city in camelódromo 1991, subsequent to the transfer of commercial employees to Independence Mall in 2011. In addition to the above, the study provides considerations about the concept of informal employment, which are the main activities performed, labor and economic situation at the time, as some exhibits about the formal labor, informal in a city center of Rio Grande do Sul.

Keywords: Informal trade; Camelódromo, Shopping Independência.

A cidade de Santa Maria, desde sua fundação, notabiliza-se por ser um local de intenso trânsito de indivíduos das mais diversas procedências e por desempenhar relevante papel no setor econômico no Rio Grande do Sul. Podemos mencionar como acontecimentos que impulsionaram isso: o advento da Viação Férrea no final do século XIX; a fundação dos aquartelamentos - com destaque para a Base Aérea de Santa Maria, na década de 1960; o grande número de instituições educacionais - com destaque para Universidade Federal de Santa Maria (UFSM) em 1960, primeira Universidade Federal a ser construída fora de uma capital estadual; e a construção do Polo Industrial, na década de $1970^{1}$.

\footnotetext{
* Acadêmico da Especialização em História do Brasil e do Mestrado em História na Universidade Federal de Santa Maria - UFSM. E-mail matheuspbutia@ hotmail.com.

** Orientador e professor do Mestrado em História na Universidade Federal de Santa Maria - UFSM.

${ }^{1}$ Ver mais em Belém (2000), Beltrão (1940), Flores (2007) Weber \& Ribeiro (2011, 2012).
} 
Ainda sobre o desenvolver da cidade, temos que destacar o elevado número de migrantes que rumaram para a cidade de Santa Maria durante as últimas décadas do século $\mathrm{XX}$. Os motivos que levaram tais hordas a direcionarem seus caminhos para os espaços urbanos são variados e trabalharemos com os preceitos de que as decisões estiveram ligadas à expectativa de maximização da renda e/ou dos empregos, aos processos combinados de atração, expulsão de centros de menor expressão, como os rurais e à ideia de que o centro urbano, mesmo que haja o conhecimento da existência de altas taxas de desemprego e subemprego, é a melhor saída, pelas oportunidades de serviços públicos (saúde, segurança e educação) de maior qualidade.

Contudo, os problemas causados pelas crises da economia nacional, nas últimas décadas do século XX, fizeram com que o mercado de trabalho se tornasse um ambiente de insegurança e tensão. Influenciadas pela ótica capitalista, algumas parcelas da sociedade, geralmente as com menor grau de instrução e poder aquisitivo, passaram a buscar saídas para resolver esses problemas. Somado a isso, Kraychete (2000) afirma que o contexto econômicotrabalhista da década de 1990 tornava mais nítido o fenômeno do desassalariamento, influenciado pela redução dos empregos assalariados com registro, devido às crises econômicas enfrentadas durante os últimos anos.

O mercado de trabalho, no Brasil, passou por uma série de reformulações que interferiram de maneira decisiva para a geração de um contingente substancial de trabalhadores vivendo "por conta própria". Assim, ocorreu uma rápida proliferação de práticas trabalhistas informais pelas ruas dos grandes centros urbanos, tendo como principais características, a mutabilidade, a informalidade e a falta de contratos de trabalho com garantias de direitos trabalhistas e sociais. A informalidade e seus efeitos não tardam a serem sentidos, uma vez que seu crescimento, somado à parca participação de órgãos reguladores e à ineficiência dos governos, acarretou em desorganização e fomentou o aparecimento de conflitos com outros setores da economia das cidades.

Compreendendo os acontecimentos econômicos dos últimos 50 anos no Brasil, é que o estudo sobre o comércio informal na cidade de Santa Maria se justifica como objeto relevante de pesquisa. As crises econômicas vinculadas ao constante crescimento da cidade e, consequentemente, do alargamento das desigualdades sociais, servem como mecanismos propulsores deste tipo de atividade. O comércio informal apresenta-se como mais um produto dos processos que tiveram início durante a expansão do capitalismo, como o êxodo rural, as desigualdades e a busca incessante por lucros e status. 
Todas essas mudanças nos âmbitos econômico, social e político do país fizeram com que o mercado de trabalho tornasse-se um campo inseguro e em constante mutação. As crescentes desigualdades nas disputas dentro da sociedade contemporânea, fomentadas pelo capitalismo predatório, acabaram diminuindo as oportunidades, potencializando a polarização social e gerando um ambiente de tensão e disputas. Sendo assim, o mercado informal desenvolve-se, principalmente, a partir do desemprego, aparecendo onde as relações capitalistas de trabalho não se encontram bem estabelecidas.

A pesquisa tem como enfoque os grupos de vendedores informais que passaram a vender seus artigos pelas ruas de Santa Maria durante estes períodos de crise. Deixamos claro o recorte, pois o setor informal engloba uma enormidade de grupos que desempenham diferentes funções como, por exemplo, os vendedores de roupas, as feiras agrícolas, os serviços de tele moto e assim por diante, sendo deveras complexo encaixá-los em um modelo único.

A informalidade como objeto de estudo apresenta um imenso leque de possibilidades para compreender a sociedade, a economia, a política, as migrações, o mundo dos trabalhos, a cultura, e as identidades. Nesta perspectiva, a história do tempo presente constitui um lugar privilegiado para uma reflexão sobre os mecanismos de incorporação do social dos indivíduos, pois tem a possibilidade de trabalhar com documentação oficial e relatos sobre os casos de indivíduos participantes do mesmo.

Acerca disto, Chartier (apud AMADO \& FERREIRA, 1998) avalia que a pesquisa de história do tempo presente causa inveja, porque argumenta que esta não é uma busca desesperada de almas mortas, mas um encontro com seres de carne e osso que são contemporâneos daqueles que lhes narram as vidas. Inveja também de recursos documentais que parecem inesgotáveis.

A história do tempo presente pode permitir com mais facilidade as necessárias articulações que tecem os laços sociais. Segundo Chauveau \& Tétart (1999), depois de ter passado a memória no crivo da crítica e ter assinalado suas fraquezas, o historiador deve analisar os erros e os mitos que ela veicula. Tomá-los tais como são, colocá-los em perspectiva histórica e fazer sua história. Em suma, para o historiador do presente, graças às testemunhas que interroga, há como tentar costurar uma arqueologia da memória coletiva.

As transformações que têm marcado o campo da história, abrindo espaço para o estudo do presente, do político, da cultura e reincorporando o papel do indivíduo no processo social, vêm estimulando o uso das fontes orais e restringindo as desconfianças quanto à sua utilização. Sobre o assunto, Montenegro (1992) salienta que a história oral apresenta-se 
válida, já que, por meio dos depoimentos, proporciona análises de elementos simbólicos que são construídos pela população. Tais depoimentos apresentam-se, muitas vezes, como o avesso daquilo que lhe é imposto cotidianamente, à medida que essa população convive, tolera, assimila e reproduz a cultura/história oficial.

Como a temática da informalidade ainda não se configura como campo muito difundido na historiografia, faz-se necessária uma breve explanação sobre a evolução do conceito de informalidade. Para tal, utilizaremos algumas considerações de pesquisadores que têm como objetos de estudo o trabalho, a economia e suas ramificações.

Sobre a questão da informalidade no mercado de trabalho brasileiro a partir dos anos 1980, Alves \& Tavares (apud ANTUNES, 2006) explanam que o conceito de setor informal originou-se a partir da formulação da Organização Internacional do Trabalho (OIT), que defendia a existência de dois segmentos: o formal, caracterizado por unidades produtivas organizadas e o setor informal, composto por unidades produtivas não organizadas.

Com o passar do tempo, diferentes análises sobre o setor informal surgiram, entre elas merece destaque o conceito de Cacciamali (1983) elucidando que, a partir dos anos 1970, o conceito de informalidade passou a ser utilizado nas análises sobre os países latinoamericanos por meio da experiência do Programa Regional de Emprego para América Latina e Caribe (PREALC). Nesse caso, a informalidade era encarada como uma estratégia residual dos agentes econômicos que foram excluídos do mercado formal de trabalho. Outra visão deste órgão entendia que no setor informal, estariam as atividades de baixo nível de produtividade e agrupava nele as categorias de trabalhadores não subordinadas à legislação trabalhista.

Neste ínterim, podemos entender que o desemprego, a ausência de políticas públicas compensatórias e o intenso êxodo rural foram alguns dos motivos que levaram a maioria das pessoas a procurar a informalidade como forma de renda. Relacionando ao objeto de pesquisa - a cidade de Santa Maria - esse pensamento sobre a informalidade se encaixa na primeira fase do crescimento dos vendedores ambulantes da cidade no início de 1980, onde havia poucos indivíduos, os quais desempenhavam atividades econômicas parcas no sentido da lucratividade baseadas necessariamente no artesanato.

Cacciamali (1983) afirma que o setor informal tornou-se um organismo subordinado ao movimento das empresas capitalistas. Para a autora, as principais características desse setor eram: 1) o trabalhador vivia de sua força de trabalho e, em alguns casos, utilizava-se do trabalho familiar ou, mais raramente, subcontratava ajudantes como extensão de seu próprio 
trabalho; 2) tinha como objetivo a obtenção de uma renda para consumo individual e familiar, visando manter também suas atividades econômicas.

O termo informal é usado para designar práticas diferentes. Sendo assim, é necessário destacarmos que os trabalhadores do comércio de rua e os ambulantes são o foco do trabalho, não desconsiderando a existência dos demais envolvidos, mas salientando a necessidade de se fazer um recorte menor para este tipo de pesquisa. Segundo Silva \& Yazbek (2006), o setor informal, a grosso modo, refere-se às atividades econômicas caracterizadas por: a) unidades produtivas baseadas no descumprimento de normas e legislação concernente a contratos, impostos, regulações e benefícios sociais; b) ocupações sem proteção social, garantias legais e estabilidade, sendo recorrente ainda, o fato de serem atividades de baixa produtividade, sem estabilidade, baixos salários - quando não se realizam sem remuneração por ação de familiares e autoemprego.

Antunes (2011) entende que houve uma tendência à subproletariazação do trabalho, presente nessas formas de trabalho precário, parcial, temporário, subcontratado, vinculados à “economia informal". Essas categorias de trabalhadores têm em comum a precariedade do emprego e da remuneração; a desregulamentação das condições de trabalho em relação às normas legais vigentes e a consequente regressão dos direitos sociais, bem como, a ausência de proteção e expressão sindicais, configurando uma tendência à individualização extrema da relação salarial.

A partir da década de 1990, observa-se um considerável crescimento da economia informal nas médias e grandes cidades brasileiras, passando a englobar um conjunto heterogêneo de trabalhadores. Paralelamente a essa aumento, tem-se o crescimento de outras formas de trabalho não regulamentadas pela legislação trabalhista, que podem ser vistas como participantes de um contexto mais amplo de precarização do trabalho.

Silva \& Yazbek (2006) afirmam que desde 1990, as principais fontes geradoras de novas ocupações foram fortemente comprimidas. Além disso, o setor privado terminou adotando novas práticas de gestão de mão de obra, como uso recorrente da terceirização. Nesses casos, essas modalidades foram favoráveis tanto ao corte de pessoal, quanto à intensificação do tempo de trabalho entre os ocupados, mesmo que recebessem salários decrescentes em termos reais.

Com este quadro, o comércio chamado de informal ganhou cada vez mais destaque nas cidades grandes. Fato este que pode ser comprovado com o grande número de "Shopping Populares" que existem nestes centros urbanos. No Rio Grande do Sul, além de Santa Maria, pelo menos três outras grandes cidades dispõem espaços destinados para tais atividades - 
Porto Alegre, Pelotas e Caxias do Sul. No entanto, devemos nos perguntar: como se deu tal processo? Quais suas motivações?

O trabalho informal em Santa Maria, nos moldes que conhecemos hoje, tem seu início no virar da década de 1980. Durante os primeiros anos, estas atividades foram desenvolvidas por pequenos grupos de artesãos locais que ficavam expondo seus trabalhos manufaturados pelas principais ruas da região central de Santa Maria. Neste momento, os principais produtos comercializados eram brincos, colares e acessórios para casa. Segundo Franchi (2012) “inicialmente não havia muita concorrência no setor, fato que auxiliou os trabalhadores na formação de uma clientela fiel e recorrente, alcançando assim maiores lucros".

Com o passar do tempo, os manufaturados deram espaço aos industrializados e, na sequência, o comércio de objetos falsificados. O grupo de vendedores informais trazia no seu interior diferenças e divisões. Neste contexto, havia segmentações dentro do grupo que desempenhava essas funções. Acerca disto, Possebon (2011) acena que os trabalhadores informais de Santa Maria,

eram subdivididos em três grupos: camelôs (que trabalhavam em bancas, na Praça Saldanha Marinho e ao longo do canteiro central da Avenida Rio Branco), ambulantes (que tinham bancas em calçadas em locais fixos ou não) e artesãos (que apesar de dividir o espaço de trabalho com ambos os grupos anteriores tem um diferencial: são regularizados) (p.37).

A partir deste crescimento, a fiscalização se tornou mais recorrente e a tensão entre vendedores formais, órgãos reguladores do governo municipal, partes da população local e outros trabalhadores informais, passou a aumentar gradativamente. Demonstrando isso, apresentamos o trecho de uma reportagem de um jornal local: “o vereador Rejane Flôres (PDS) solicitando maior fiscalização do comércio ambulante nas ruas centrais da cidade. $\mathrm{Na}$ opinião do pedessista, o Centro estava uma verdadeira baderna, com um festival de lixo e contrabandistas" (O Expresso, 1990, p. 09).

O conflito entre comerciantes formais e informais pode ser comprovado por meio das reclamações feitas por alguns lojistas da cidade, que, em suma, não achavam justa a disputa entre os envolvidos no processo, pois, em muitos casos, os vendedores ambulantes postavamse nos arredores de grandes lojas da cidade desenvolvendo lá suas atividades comerciais. Os mesmos não pagavam impostos sobre as mercadorias, apenas um piso para a prefeitura do município para trabalhar nas ruas, e, na maioria das vezes, comercializavam produtos falsificados com menor preço que o produto vendido pelo comerciante formal. 
As poucas barraquinhas de antes aumentaram de número, os produtos comercializados também mudaram e os conflitos não paravam de potencializarem-se. As pressões de alguns setores da sociedade santa-mariense (vendedores formais, informais e pedestres) no governo municipal eram cada vez mais fortes e recorrentes e, neste contexto, foi decidido que seria fundado um mercado público na região central da cidade.

A partir de meados da década de 1990, a situação da informalidade em Santa Maria tornou-se praticamente incontrolável, pois as atividades sem vínculo duradouro e sem a perseguição tributária apresentaram-se como a saída para os momentos de crise.

Acerca dos fatores que levaram o poder público a criar um centro comercial destinado às práticas informais, além das mencionadas querelas entre formais e informais, surgiram questões urbanas, turísticas e a dos próprios camelôs. Pelo viés estético, a presença de barracas pelas calçadas e nas ruas da região central acabava por prejudicar o trânsito de pedestre e as atividades turísticas. Acerca disto, afirma Possebon (2011):

O primeiro local planejado para o camelódromo municipal foi entre a Praça Saldanha Marinha e a Rua dos Andradas, na Avenida Rio Branco. Com este projeto, os camelôs que se dispunham na Avenida apenas trocariam de lado e os da Rua do Acampamento seguiriam num local central, sendo que, o modelo de construção era pensado em módulos (p. 44).

O projeto foi elaborado rapidamente e a maioria dos ambulantes concordou com a mudança, pois eles acreditavam nos benefícios prometidos, seja ou financeiramente, ou na organização ou na segurança. Contudo, no outro extremo, havia alguns vendedores que não achavam que a mudança seria benéfica, pois perderiam sua liberdade.

Mesmo com esse impasse, após a decisão da criação do Camelódromo, a Prefeitura Municipal de Santa Maria deixou de expedir alvarás de liberação para o comércio nas ruas da cidade, buscando assim, controle e o impedimento do aumento do número de camelôs. Deste modo, apenas aqueles que estivessem legalmente cadastrados iriam para o Camelódromo e, após sua construção, a prefeitura prometia fiscalizar e punir com severidade os que tentassem desenvolver as atividades fora do dele.

Após um debate entre o governo municipal e os vendedores ambulantes, foi tomada a decisão que o Camelódromo seria construído na mesma Avenida Rio Branco e caberia à Associação dos Ambulantes de Santa Maria (ACASM) a divisão e instalação dos vendedores dentro do mesmo. As obras do Camelódromo municipal de Santa Maria foram concluídas em meados de 1991, tendo atrasado alguns meses do que havia sido previsto no início do projeto. Sobre isto, o secretário interino informou em reportagem do Jornal O Expresso (1991) que, 
o Camelódromo atenderá cerca de 60 camelôs, que atualmente se encontram distribuído na Rua do Acampamento, na Avenida Rio Branco, Alberto Pasqualini e imediações da Rodoviária. Todos os Box ou casinha abrigará dois vendedores, haverá também um Box no Camelódromo para a administração e outro para segurança e banheiro (p. 11).

As regras impostas pela Prefeitura Municipal eram claras e faziam parte de um posicionamento mais rígido. A ideia era erradicar o comércio desordenado pelas ruas de Santa Maria e possibilitar melhores condições aos trabalhadores informais.

Os primeiros anos de Avenida Rio Branco se apresentaram de forma tranquila, não existindo críticas no sentido de infraestrutura. Segundo o depoimento de um comerciante informal, "na Avenida Rio Branco, na época da fundação, foi feito tudo muito bem estruturado" (Mafalda, 2012). A ideia de dois comerciantes por quiosque era seguida à risca durante os primeiros tempos. Contudo, no sentido de lucratividade e organização interna dos camelôs, os primeiros momentos não foram de sucesso. Um dos entrevistados afirma que, "no início foi terrível. Porque tu tava [sic] acostumado com um espaço bem maior e com uma clientela já estabelecida. Foi bem difícil nos primeiros tempos” (Mafalda, 2012).

Outro ponto que atrapalhou, nos primeiros tempos de Camelódromo, foi a permanência de vendedores pelas ruas de Santa Maria. Isto é, houve apenas uma substituição de agentes. No lugar daqueles 57 ambulantes que foram para o centro comercial, outros ocuparam o antigo espaço. Este fato foi reflexo do contexto econômico e trabalhista do país. Segundo Kraychete (2000),

nos anos de 1990, todas as regiões brasileiras apresentaram taxas de desemprego que são, no mínimo, o dobro das verificadas no final da década de 1980 [...]. O crescimento do desemprego foi acompanhado por uma modificação na composição da estrutura ocupacional, com uma diminuição gradativa, desde os anos de 1980, da mão de obra empregada na indústria e no setor primário, e um aumento do terciário, que cresce deteriorando-se, absorvendo ocupações instáveis e mal remuneradas (p.17-18).

A constante crise econômica causou um gradual alargamento das atividades informais, tanto em Santa Maria, como no país inteiro. A organização inicial para cerca de 60 vendedores demonstrou-se insuficiente com o passar dos anos. A fiscalização também não conseguiu dar conta da demanda e nem mesmo a organização interna dos vendedores mantinha níveis recomendáveis.

Na virada do século XXI, a situação dos vendedores informais já era tida como algo prejudicial para a cidade. Não havia controle do que se comercializava no Camelódromo, 
tampouco os comerciantes achavam que aquela situação era correta. A antiga localização havia sido alargada para mais uma quadra abaixo. Não somente o trecho entre a Rua Venâncio Aires e a Rua dos Andradas comportava o centro comercial informal, a quadra da Rua Silva Jardim também era tomada por aquelas barracas e suas lonas de cor laranja.

Além disso, o comércio pelas esquinas do centro da cidade permanecia a todo vapor. Os CDs e DVDs eram facilmente encontrados e a fiscalização nada fazia para impedir tal comércio, pois a participação da mesma, no Camelódromo, também era quase inexistente. $\mathrm{O}$ quadro não permitia demora na tomada de atitudes. O Poder Executivo Municipal estava sob o comando do Prefeito Valdeci de Oliveira (PT - Partido dos Trabalhadores) que passou a ser o alvo de cobranças pela situação do Camelódromo no centro da cidade. Sendo assim, segundo Mafalda (2012),

um projeto visando a retirada dos vendedores informais da Avenida Rio Branco passou a ser elaborado. Depois de 15 anos, uma nova mudança seria proposta e todas as partes envolvidas esperavam que não somente o local fosse mudado, mas também a realidade do comércio informal de Santa Maria.

A fundação do Camelódromo não foi mais do que um 'tapa-furo', ou seja, uma solução de momento, já que a situação econômica/trabalhista vivida era caótica e apenas potencializou os problemas. Com uma fiscalização praticamente inexistente e a organização muito aquém do necessário, o crescimento se tornou incontrolável. Aquilo que seria a solução se apresentou como um problema que novamente ofereceria fragilidades para a população da cidade.

A partir de meados de 2005, as notícias sobre o Shopping Popular tornaram-se recorrentes na internet. Todavia, os jornais da época pareciam ignorar a temática, fazendo com que as fontes dos acontecimentos fossem basicamente advindas da internet. A primeira notícia da qual se teve acesso tratava de um encontro do Prefeito Municipal Valdeci de Oliveira (PT) com os vendedores informais de Santa Maria para discutir a implementação do Shopping Independência,

Valdeci conversou com os camelôs e ambulantes. As duas audiências duraram cerca de uma hora e trinta minutos. Nas reuniões, Valdeci esclareceu que o projeto apresentado é um esboço e que há possibilidade de sugestões e modificações. O prefeito afirmou que o projeto inicial prevê a existência de 194 estandes no Shopping Popular distribuídos em três pavimentos, sendo que cada categoria atuaria em um andar determinado, conforme reivindicação feita pelos trabalhadores ao Executivo. 
Ainda no ano de 2005, o prédio onde funcionava o antigo Cine Independência foi escolhido como o local do Shopping Popular na cidade e a compra foi concluída pelo Poder Executivo Municipal no mesmo ano. Os valores giraram em torno de 1,2 milhões de reais que seriam pagos em 22 parcelas, sendo 21 parcelas de 55 mil reais e a última de 45 mil. A transferência dos vendedores informais da Avenida Rio Branco para o Shopping Popular não resultava somente de motivações econômicas e de segurança. A (re)organização urbana também estava em pauta. Tendo sido um dos cartões postais de Santa Maria, imponente e majestosa em tempos de ferrovia, a Avenida Rio Branco - anteriormente Avenida Progresso convivia com dias nebulosos. A proliferação das bancas com suas lonas chamativas deixava aquele espaço de passeio urbano cinzento e 'mal habitado'.

A situação de tensão entre os vendedores informais e o poder público passava a ser constante. O discurso do Prefeito Municipal era de erradicar os problemas enfrentados por estas práticas. Para tal, tornou-se recorrente a apreensão de artigos comercializados nas ruas da cidade. Com este crescimento desordenado, era claro que o controle do espaço não seria fácil, tampouco rápido. De acordo com reportagens de jornais locais, esperava-se que, em 2007, as obras do Shopping Popular estivessem prontas, uma vez que

[...] os santa-marienses serão contemplados com mais um importante projeto, o Shopping Popular, que vai destinar espaços de comercialização para artesãos, camelôs e vendedores ambulantes. $O$ [...] Shopping Popular terá outros atrativos, como um espaço destinado à realização de eventos culturais no andar térreo e uma praça de alimentação no segundo andar. No último pavimento, junto com o restante dos estandes, deverá ficar a administração do shopping.

Além do interesse político e de reordenação urbana, havia o viés econômico da empreitada, não apenas se referindo aos ambulantes, mas também da parceria firmada entre a Prefeitura Municipal e a Rede de hipermercados francesa Carrefour, a ser fixada próxima aos vendedores ambulantes. Tal empresa fez um acordo que ajudaria no levantamento das obras do Shopping Popular com a quantia de um milhão de reais. O total de investimentos para a implantação do Shopping foi de cerca de R \$ 1,3 milhão. A obra de restauração do prédio, na Praça Saldanha Marinho, foi realizada pela BK Construções, mesma empresa que trabalhou para a instalação do Carrefour. O Hipermercado firmou a parceria por meio da destinação de R\$ 1 milhão, a fundo perdido, como contrapartida pelos investimentos no município. $\mathrm{O}$ valor restante foi proveniente de uma emenda parlamentar do Deputado Federal Paulo Pimenta, por meio do Projeto de Inclusão Produtiva do Ministério do Desenvolvimento Social (MDS). 
Na concepção do governo, o Shopping Popular seria a solução para as fragilidades no centro da cidade (segurança, emprego formal, iluminação, e revitalização da Avenida Rio Branco). Também haveria maior controle na fiscalização do comércio informal, além disso, a ideia de que todos os vendedores fossem contribuintes tributários, como os outros setores do comércio local. Segundo Possebon (2011) as

[...] obras do Shopping Popular [ainda sem nome na época], o qual seria instalado no antigo Cine Independência [na Praça Central] e contaria com uma área de 1050 metros quadrados, abrigando 194 bancas. O projeto prometia 'tirar os profissionais das ruas, além de dar melhores condições de atuação, com a qualificação das alternativas de geração de trabalho e renda'. Anunciava-se que poderiam ir para o local todos os trabalhadores informais que já fossem cadastrados no município, fossem eles camelôs, artesãos ou ambulantes (eram cerca de 100 camelôs, 56 ambulantes e 50 artesãos cadastrados) (p. 61).

Contudo, nem todas as expectativas estavam sendo cumpridas. Nem na organização dos vendedores informais, que permanecia caótica e em expansão pelas ruas da cidade, nem nas obras do Shopping Popular, as quais não estavam sendo prosseguidas como era esperado. Além desta preocupação com as obras do Shopping Popular, o prefeito Cezar Schirmer (20082012) demonstrava a intenção de legalizar os vendedores informais da cidade, por meio de uma lei ou de um decreto.

Apenas em novembro de 2009, a Prefeitura Municipal publicou o edital para a abertura de licitação para a contratação da empresa que concluiria as obras internas do Shopping Popular. A empresa vencedora era obrigada a cumprir, no prazo de três meses, as reformas planejadas e, com seus recursos, deixar o espaço apto para as práticas comerciárias o mais rápido possível. A vencedora da licitação foi a empresa CPC, de Santa Maria, a única que decidiu participar da disputa e conseguiu o direito de administrar o local durante dez anos, com a possibilidade de prorrogação de mais dez anos.

Com as obras encaminhadas, a atenção do governo se voltou para outro lado e um dos focos que seria fortemente combatido após a transferência para o Shopping Independência, seria a pirataria. Era de conhecimento público que um dos principais meios de obtenção do lucro dos Camelôs era com os produtos ilegais (óculos, brinquedos, eletroeletrônicos, roupas, calçados, relógios, bonés, etc.) que vinham, principalmente, de grandes centros como São Paulo e Rio de Janeiro, bem como de outros países, como o Paraguai. 
Nota-se que, naquele momento, já havia se tornado difícil qualquer forma de questionamento acerca da mudança programada para os vendedores informais da cidade. Era apenas uma questão de tempo para que todos os artesãos, ambulantes e Camelôs de Santa Maria fossem realocados. Todavia, não havia como deixar de ouvir os próprios vendedores informais nesse processo de mudança física de seus estabelecimentos. Como eles entendiam essas mudanças? Eles aceitavam trocar de lugar novamente? O governo pediu sua participação na elaboração do projeto e levou em conta as necessidades dos mesmos?

Uma das maiores reclamações dos Camelôs foi a total falta de diálogo entre o governo municipal e os maiores interessados. Nem o nome do Shopping foi escolhido por eles, o que denuncia o quão unilateral foi as decisões sobre o futuro do comércio informal em Santa Maria.

Muitos comerciantes não queriam sair da Avenida Rio Branco, mesmo sabendo que a situação do Camelódromo seria insustentável. As críticas não cessavam para ambos os lados dessa querela, afinal, a postura tomada pela prefeitura, não foi nem democrática, nem respeitosa. Os vereadores Sérgio Cechim (PP) e João Carlos Maciel (PMDB) expuseram suas opiniões: "Faltou diálogo, faltou bom senso, [...] Faltou que uma comissão se apresente e convença os camelôs que vai ser ótimo aqui”. Por seu turno, a empresa responsável pelas obras do Shopping (CPC), afirmava: “a empresa é responsável somente pela conclusão da obra e pela administração. A negociação com os camelôs e com os artesãos é com a prefeitura" (Jornal A Razão, 2010).

O receio de que essa transferência não transcorresse de forma tranquila e harmoniosa não se confirmou, pois a maioria dos vendedores informais enxergava a mudança com bons olhos. Para eles, ir para o Shopping Independência seria benéfico, mesmo que este não apresentasse as condições recomendáveis como o espaço e a liberdade que conviviam no Camelódromo. A prefeitura prometia que as fragilidades seriam sanadas o mais rápido possível e que a mudança de ares era inevitável.

Os meses que seguiram foram de últimos retoques na estrutura do Shopping e nas tentativas de alguns poucos vendedores permanecerem comercializando na rua. Entretanto, a realidade parecia ser diferente e a Prefeitura Municipal deixava clara sua ideia de erradicar por completo o comércio pelas ruas de Santa Maria. Ou seja: ou os vendedores facilitavam e se transferiam para o novo centro comercial ou corriam o risco de ficar sem rendimentos.

Era questão de tempo para que o novo lugar de trabalho dos camelôs estivesse a pleno vapor. Os boxes foram divididos em cinco setores: Setor A, com seis boxes no valor de $\mathrm{R}$ \$ 490,00; B, com sessenta e seis boxes no valor de R \$ 300,00; C, com três boxes no valor de 
$\mathrm{R} \$ 250,00 ; \mathrm{D}$ com trinta e sete boxes no valor de $\mathrm{R} \$ 150,00$ e dez no valor de $\mathrm{R} \$ 160,00$ e; Setor E com trinta e seis boxes no valor de $\mathrm{R} \$ 105,00$ e dezenove boxes no valor de $\mathrm{R} \$$ 145,00

A esperança de dias melhores e de mais organização era o mote principal dos trabalhadores. A Avenida Rio Branco deixaria de comportar aquela imensidão de lonas e penduricalhos na sua extensão. O lugar onde seria estabelecido o comércio informal seria de melhor localização e acesso para a população santa-mariense, os problemas de ordem legal seriam sanados e as perspectivas eram as melhores. Sabe-se, porém, que nem sempre a realidade acompanha os desejos.

No dia 25 de junho de 2011, foi inaugurado o Shopping Independência, o primeiro mercado público da cidade de Santa Maria, semelhante aos que existem em outros grandes centros do país com trabalho em ritmo acelerado. Era um novo momento na vida desses trabalhadores e todos só desejavam que as mudanças terminassem e que pudessem desenvolver suas atividades de forma tranquila e segura.

Mas o que está diferente do Camelódromo? Muitos dizem que a organização, a segurança, a estética e o público. Partilha-se com alguns pontos, mas há dúvidas de que a solução final seja o Shopping Independência ou, como é conhecido por grande parcela da sociedade santa-mariense, o Shopping 'Popular', já que, quando fundado, o Camelódromo também gozava das mesmas prerrogativas. Isso, porém, não há como mensurar a curto prazo.

O que se pode notar é que as condições do Shopping Independência não são totalmente recomendáveis. Atualmente, faltam alguns elementos que possibilitem boas condições para os vendedores e consumidores, pois o espaço é mínimo, as instalações de segurança não são as aconselháveis e a divisão, por andar, permanece atrapalhando no desenvolvimento das atividades.

Mesmo assim, o chamado comércio informal não terá fim, pelo menos não tão cedo. No lugar daqueles que estão hoje, no Shopping Independência, chegarão outros e mais outros, fazendo com que seja necessária a construção ou a remodelação do atual local destinado a esses trabalhadores.

\section{Referências Bibliográficas}


ALVES, Maria Aparecida. "Setor informal" ou trabalho informal? Uma abordagem crítica sobre o conceito de informalidade. Campinas, 2001. Dissertação (Mestrado em Sociologia), Instituto de Filosofia e Ciências Humanas, Universidade Estadual de Campinas.

AMADO, Janaína; FERREIRA, Marieta. Usos e abusos da história oral. Rio de Janeiro: Getúlio Vargas, 1996.

ANTUNES, Ricardo. Adeus ao Trabalho? Ensaio sobre as metamorfoses e a centralidade no mundo do trabalho. 15. ed. São Paulo: Cortez, 2011. . (org.). Riqueza e Miséria do trabalho no Brasil. São Paulo, Boitempo, 2006.

BEBER, Cirilo, Santa Maria 200 anos: história da economia do município. Santa Maria, Pallotti, 1998.

BELÉM, João. História do Município de Santa Maria (1797-1933). Santa Maria: UFSM, 2000.

BELTRÃO, Romeu. Cronologia Histórica de Santa Maria do extinto Município de São Martinho 1781-1930. $2^{\circ}$ ed. Santa Maria: Globo, 1940.

CACCIAMALI, M. C. Setor informal urbano e formas de participação na produção. São Paulo, Instituto de Pesquisas Econômicas, 1983.

. Globalização e processo de informalidade. In: Economia e Sociedade. Campinas, IE/UNICAMP, n. 14, jun. 2000, p. 152-74.

CASTELLS, Manuel. A questão urbana. Rio de Janeiro: Paz e Terra, 1980.

CHAUVEAU, A; TÉTARD, Ph. Questões para a história do tempo presente. Bauru, SP: Edusc, 1999.

FERREIRA, Marieta de Moraes (org.) Entre-vistas: abordagens e usos da história oral. Rio de Janeiro - RJ: Ed. Fundação Getúlio Vargas, 1994.

FLÔRES, João Rodolpho Amaral. Fragmentos da história ferroviária brasileira e Rio-grandense: fontes documentais, principais ferrovias, Viação do Rio Grande do Sul (VFRGS), Santa Maria, a "Cidade Ferroviária”. Santa Maria, RS: Pallotti, 2007.

FRANCHI, Miguel A. Entrevista prestada ao pesquisador Matheus Rosa Pinto, 2012.

Jornal A Razão. Prefeitura não volta atrás. 20 mai. 2010. Disponível em: <http://arazao.com.br/economia/prefeitura-nao-volta-atras/> Acesso em: 06 abr. 2012.

Jornal O Expresso, Santa Maria, p. 09, 30/31 mar. de 1991.

Jornal O Expresso, Santa Maria, p. 11, 26/27 jan. de 1991.

Jornal O Expresso, Santa Maria, p. 17, 08/09 dez. de 1990.

KRAYCHETE, G. (Org.). Economia dos setores populares: entre a realidade e a utopia. Petrópolis: Vozes; Rio de Janeiro: Capina; Salvador: CESE: UCSAL, 2000.

MAFALDA, José. Entrevista prestada ao pesquisador Matheus Rosa Pinto. Santa Maria, 2012.

MONTENEGRO, Antônio T. HISTÓRIA ORAL E MEMÓRIA: a cultura popular revisitada. Coleção Caminhos da História, São Paulo: Contexto, 1992.

POCHMANN, Márcio, O Trabalho sob fogo cruzado. São Paulo: Contexto, 2000.

POSSEBOM, Daniela. Do Camelódromo ao Shopping Popular Independência: uma breve história do comércio informal em Santa Maria. Santa Maria: UFSM, 2010. Monografia do curso de História, Universidade Federal de Santa Maria. 125 p.

SILVA, Maria; YAZBEK, Maria (org.). Políticas públicas de trabalho e renda no Brasil Contemporâneo. São Paulo: Cortez; São Luís, MA: FAPEMA, 2006. 
SINGER, PAUL. Globalização e Desemprego: diagnósticos e alternativas. 6. ed. - São Paulo: Contexto, 2003.

TAVARES, Maria Augusta. Os fios (in)visíveis da produção capitalista: informalidade e precarização do trabalho. São Paulo: Cortez, 2004.

WEBER, Beatriz, RIBEIRO, José Iran (Org.). Nova História de Santa Maria: contribuições recentes. Santa Maria, UFSM: 2011.

Nova História de Santa Maria: contribuições recentes. Santa Maria, UFSM, 2012. 